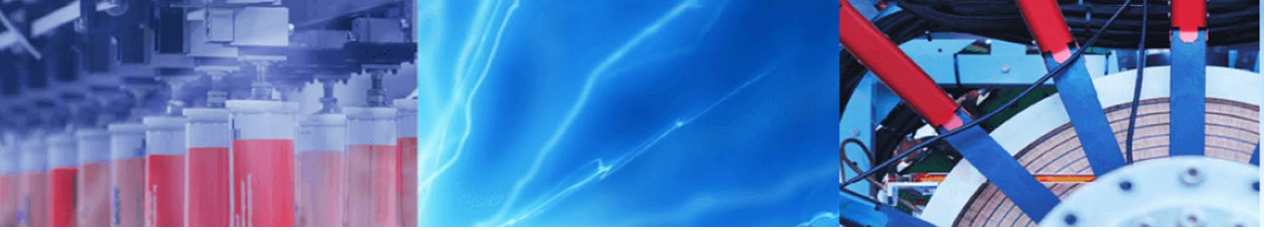

Short Communication

\title{
Synthesis of novel cone-shaped CaAl-LDH directly on aluminum alloy by a facile urea hydrolysis method
}

\author{
Muhammad Ahsan Iqbal ${ }^{1,2}$ (D) Luyi Sun $^{2} \cdot$ Michele Fedel $^{1}$
}

(c) Springer Nature Switzerland AG 2019

\begin{abstract}
The urea method is one of the unique approaches to synthesize highly crystalline-layered double hydroxides (LDHs). Herein, we synthesized calcium-based layered double hydroxide (CaAl-LDH) directly on AI AA6082 substrate by using the urea hydrolysis reaction, in an effort to obtain highly potential novel cone-shaped unique LDH structure. The asprepared CaAl-LDH thin film is characterized by X-ray diffraction, Fourier transform spectroscopy, scanning electron microscopy, transmission electron microscopy and further investigated the thermal properties and electron impedance spectra behavior. That simple in situ synthetic approach will be helpful to design environmentally friendly CaAl-LDH thin films that can be further investigated for numerous potential applications like environmental science, catalysts and biomedical applications.
\end{abstract}

Keywords Urea hydrolysis · Cone-shaped CaAI-LDH thin film · In situ growth

\section{Introduction}

Layered double hydroxides (LDHs), considered as ordered layered materials, have been widely investigated in different research fields, for instance, drug delivery system [1], protective coatings [2, 3], environmental sciences [4], adsorption [5, 6] and as catalysts [7], due to their compositional versatility, wide range of structural availability and flexible choice of compositional cations and anions. Layered double hydroxide is represented by a general expression $\left.\left[\mathrm{M}_{1-x}^{2+} \mathrm{M}_{x}^{3+} \cdot x(\mathrm{OH})_{2}\right] \mathrm{A}_{x / n}^{\mathrm{n}-} \cdot \mathrm{mH}_{2} \mathrm{O}\right]$ and consists of positively charged layers of mixed metal hydroxides, where some of the divalent $\left(\mathrm{M}^{2}\right)$ cations are substituted with trivalent $\left(\mathrm{M}^{3}\right)$ cations, while the net positive charge is compensated through anions $\left(A_{n}\right)$ intercalations, and results in the formation of brucite-like structure [3]. Generally, two different approaches are employed to synthesize layered double hydroxide system, i.e., co-precipitated [8] and in situ growth method [9]. The conventional hydrothermal approaches lead to the formation of either hexagonal platelet structure or sand-rose surface morphology. In our recent work, we developed different LDH surface morphologies, for instance, cauliflower, stone-like structure, with the variation of synthetic parameters [3]. Dutta et al. designed the hydrophobic cone-shaped structure modified by dodecyl sulfate ions to enhance the absorption capacity of CaAl-LDH through the co-precipitation method [10]. Recently, we investigated CaAI-LDH, exhibiting various surface morphologies, grown directly on an aluminum substrate to investigate the corrosion resistance properties [11]. It has been reported that well-crystallized, highly active LDH can also be synthesized by urea hydrolysis method and can be considered as an efficient approach to design a highly oriented LDH structure $[12,13]$. In the present study, novel cone-shaped CaAl-LDH is synthesized on the aluminum substrate by single-step urea hydrolysis method. Urea is found to impart some excellent features in the formation of LDH and can be helpful to modify the

$\triangle$ Muhammad Ahsan lqbal, muhammadahsan.iqbal@unitn.it | 'Department of Industrial Engineering, University of Trento, Via Sommarive 9, Povo, TN, Italy. ${ }^{2}$ Polymer Program, Institute of Materials Science and Department of Chemical and Biomolecular Engineering, University of Connecticut, Storrs, CT 06269, USA. 
textural properties, often resulting in the mono-dispersed particle distribution and uniform precipitation due to the hydrolysis of urea upon the thermal treatment [14]. From the last few years, LDH structure ranging from the nanosize spheres and platelet structures to LDH belts are formed to utilize it in various applications. This study is the example of a single-step facile formation of cone-shaped, well-ordered CaAl-LDH grown directly on aluminum substrate. The major advantages of CaAl-LDH formed by urea hydrolysis method are as follows: (1) single-step in situ cone-shaped LDH synthetic route, (2) wel- ordered, morphological alteration along with homogenous particles for numerous applications in the fields of nanomaterial's and composites and (3) cone-shaped LDH particles with preferential growth perpendicular to the substrate, with crystallite size distribution much narrower than conventional co-precipitation methods.

\section{Synthesis of nanocones CaAI-LDH}

The cone-shaped CaAl-LDH thin film was grown through the urea hydrolysis approach. In general, the aluminum specimen $\left(3.14 \mathrm{~cm}^{2}\right)$ was initially ground from 500 to 1000, 2400 grit SiC paper, respectively, and was washed with deionized water and further was treated ultrasonically in pure ethanol for $10 \mathrm{~min}$. Finally, the specimens were etched by using $0.1 \mathrm{M} \mathrm{NaOH}$ solution for $1 \mathrm{~min}$. The pretreated aluminum substrate actually acts as the source of $\mathrm{Al}^{+3}$ which provides a building block for the synthesis of $\mathrm{LDH}$ on it. $0.03 \mathrm{M} \mathrm{CaNO}_{3} \cdot 4 \mathrm{H}_{2} \mathrm{O}$ and $0.18 \mathrm{M}$ urea (1:1) were prepared and were transferred into $100 \mathrm{~mL}$ Teflonlined autoclave, while the pretreated aluminum substrates $\left(3.14 \mathrm{~cm}^{2}\right)$ were placed in the prepared solution and were treated in an oven at $120^{\circ} \mathrm{C}$ for $18 \mathrm{~h}$. The initial pH of the prepared solution was 5.36 , which on completion of the experiment approached 9.7.

\section{Characterization}

The nanocone-shaped CaAl-LDH thin-film structure was confirmed by the scanning electron microscopy (JEOL JSM-6330F) and transmission electron microscopy (FEI Talos F200X). The X-ray diffractometer (Bruker D5005, $\lambda=1.5406 \AA^{-1}$ ) was used to characterize the crystal structure. The surface functional groups of the film were recorded by FTIR (NICOLET MAGNA 560) in ATR mode. The TGA analysis of CaAl-LDH was obtained by using TA instruments [TGA Q5000 IR thermobalance (New Castle, $D E$, USA)] with a sample size of $7 \mathrm{mg}$ (scraped from the coated specimen) at a heating rate of $10^{\circ} \mathrm{C} / \mathrm{min}$ under air flow $(10 \mathrm{~mL} / \mathrm{min})$, while DSC analysis was studied through Mettler DSC30 calorimeter (Columbus, OH, USA), using $10 \mathrm{mg} \mathrm{CaAl-LDH}$ powder under an air flow of $10 \mathrm{~mL} /$ min up to $600{ }^{\circ} \mathrm{C}$ temperature. EIS measurements were acquired by using PAR (Parstat 2273 equipment) for a frequency range of $100 \mathrm{kHz}-10 \mathrm{mHz}$, with an amplitude perturbation of $5 \mathrm{mV}$ (rms). The measurement was performed in $0.1 \mathrm{M} \mathrm{NaCl}$ solution at ambient conditions.

\section{Results and discussion}

Figure 1a-c depicts the CaAI-LDH SEM images. It can be seen that LDH microcrystal's uniformly covered the entire aluminum substrate surface, and well-developed nanocone-shaped structure is formed on the Al 6082 substrate. This phenomenon is particularly evident in the high-resolution SEM micrographs (Fig. 1b-c), where nanocone-shaped morphology can clearly be observed. Figure $1 \mathrm{~d}$ shows a cross-sectional analysis of LDH film, depicting the average thickness of $10.30 \mu \mathrm{m}$. The particle size distribution lies in the range of 1.6-3.2 $\mu \mathrm{m}$. Further, the TEM images were recorded to evaluate the morphological characteristics of $L D H$, as shown in Fig. 1e, f. The TEM analysis was performed for the CaAI-LDH scraped from the substrate, and during sample preparation, the scraped LDH was dispersed in the ethanol. The ultrasonication may cause the destruction of the cone-like structure of most crystals; however, characteristic features of LDH can be seen and the layered structure of $\mathrm{LDH}$ is dominant in Fig. 1f. The hydrolysis of urea increases at high temperature, i.e., $120^{\circ} \mathrm{C}$, and caused an increase of $\mathrm{pH}$ of the synthetic solution found to favor the formation of $\mathrm{LDH}$ on the aluminum substrate. Usually, carbonate ions have also been reported inside the LDH layers when synthesized by urea hydrolysis method; however, here FTIR analysis did not show the characteristics peaks of carbonate ions. The previous studies have shown that high-temperature synthesis may favor the intercalation of nitrate ions (present in the solution) in the LDH interlayer's [15]. The XRD pattern of CaAl-LDH is shown in Fig. 2a, where distinct reflection peaks at $2(\theta) 12.29^{\circ}, 24.1^{\circ}$, correspond to (001) and (002), respectively, and can be seen which confirmed the CaAl-LDH structure [16]. In addition to the CaAl-LDH peaks, there can also be seen TCA (tricalcium aluminates), because it is arduous to synthesize thermodynamically pure CaAl-LDH phase due to the favor of different secondary phases during the CaAl-LDH synthesis. It is well revealed that $\mathrm{Ca}^{2+}$ in CaAl-LDH is coordinated heptahedrally with the $\mathrm{Al}$, due to relatively large size of $\mathrm{Ca}^{2+}[17]$.

The "001" reflection peak at $2(\theta)$ of $12.29^{\circ}$ indicated a basal spacing of $0.72 \mathrm{~nm}$. The resultant basal spacing is specific for the family of LDHs, where positively charged layers interlayer anions hold the $\mathrm{OH}^{-}$[19]. Here, the basal 
Fig. 1 a-c SEM images, $\mathbf{d}$ optical image of the cross section of CaAl-LDH, e, $\mathbf{f}$ TEM images of $\mathrm{LDH}$


Fig. 2 a XRD pattern of the CaAl-LDH film samples developed on AA6082, b FTIR spectrum of CaAl-LDH (scrapped from the aluminum substrate) 
spacing did not correlate with the traditional $\mathrm{NO}_{3}^{-1}$ spacing, possibly due to the following reasons: (1) the anions intercalation varies in terms of orientations, for instance, nitrate anions can intercalate in three specific orientations from "flatter" to "stacked" orientation. Among them, flatter orientation can show a reduction in basal spacing [18], (2) the water molecules are trapped inside the interlayers along with anions in various fashions, which affect the d-spacing. (3) Nitrate anions can be absorbed on the diffuse electrical layers of LDH. Further, the formation of tricalcium aluminate (TCA) may cause the suppression of nitrates inside the interlayer's $[16,19]$. However, FTIR analysis has shown the characteristics peak of $\mathrm{NO}_{3}{ }^{1-}$ groups and confirmed the presence of nitrate groups in the LDH system. It seems that TCA formation caused suppression of nitrate intercalation and nitrate groups adsorbed on the diffused electrical layers.

FTIR analysis is shown in Fig. 2b, and the broadband displayed in the range of $3370-3427 \mathrm{~cm}^{-1}$ are assigned to $\mathrm{OH}$ group stretching, while the absorption band around $1627-1633 \mathrm{~cm}^{-1}$ is caused due to the flexural oscillation peaks of interlayer water molecules [20]. Moreover, the absorption peaks around $1389 \mathrm{~cm}^{-1}$ are assigned to the asymmetric stretching bond of intercalated $\mathrm{NO}_{3}^{-1}$ [21]. The bond at 655,751 and $1202 \mathrm{~cm}^{-1}$ may associate with the $\mathrm{Al}-\mathrm{OH}$ stretching [22]. The absorption peaks around $550-770$ correspond to the lattice vibration of metal-oxygen bonds (M-O) [23]. The obtained findings of FTIR are also well consistent with the TGA-DSC, XRD and SEM analysis. The TGA-DSC results (Fig. 3a) describe the $\mathrm{LDH}$ structural decomposition, which in general eventuates in two stages: Initially, the dehydration of the interlayer water molecules took place, around $200^{\circ} \mathrm{C}$, while on a later stage, the decomposition of interlayer anions and dehydroxylation occurs (temperature range $200-600^{\circ} \mathrm{C}$ ). This statement well correlates with the TGA-DSC thermograms in the previous reports related to LDH [24]. The increase in mass loss $(40 \%)$ is due to the fact that there are more bounded anionic species, and the results correspond to the FTIR analysis. The EIS measurements of as-prepared CaAI-LDH are shown in Fig. 3b, and the higher value of impedance in the low-frequency domain (impedance modulus at $0.01 \mathrm{~Hz},|\mathrm{Z}|_{0.01}$ ) roughly indicates higher resistance properties. In the insets of Fig. $3 b$, the phase angle response is presented. Considering the EIS response of the samples, two relaxation processes can be observed in the phase angle spectrum (Fig. 3b): The time constant in the high-frequency range $\left(10^{3}-10^{4} \mathrm{~Hz}\right)$ can be attributed to the properties of the $\mathrm{LDH}$ layer itself, while the time constants in the middle frequency range $10^{0}-10^{1} \mathrm{~Hz}$ are the overlapping of the contributions of the aluminum oxide and of the faradic process of substrate and solution interphase.

The co-precipitated CaAl-LDH powders are actively investigated as catalysts, biomedical applications and so on $[25,26]$. The advantages of novel cone-shaped CaAI-LDH films grown on the metallic substrate will be helpful for the design of potentially active LDH for above-said applications, owing to the unique structure, preferential growth and geometry due to the activated structure. In a nutshell, this work gives an insight on the in situ grown cone-shaped $\mathrm{CaAl}-\mathrm{NO}_{3}-\mathrm{LDH}$ structure, and the geometry capable to modify further with inorganic and organic ions due to low ion exchange equilibrium constant of interlayer $\mathrm{NO}_{3}^{-1}$ anions.
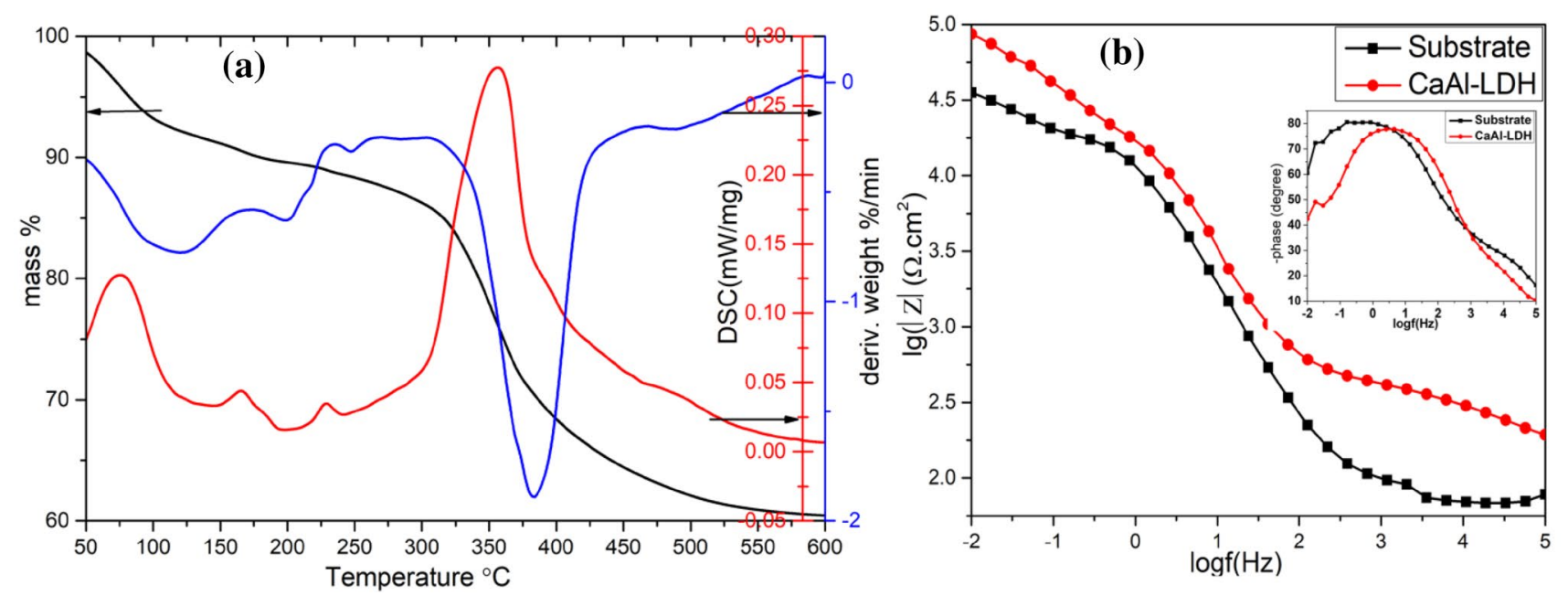

Fig. 3 aTGA-DSC thermograms of the as-prepared cone-shaped CaAl-NO3-LDH (powder scraped from the specimen), b Bode plots in $0.1 \mathrm{M} \mathrm{NaCl}$ solution 


\section{Conclusion}

In summary, we describe the development of cone-shaped $\mathrm{CaAl}-\mathrm{NO}_{3}-\mathrm{LDH}$ on AA6082 using the urea hydrolysis method. The XRD and FTIR analysis confirmed the formation of CaAl-LDH on the aluminum surface, while microscopic studies have shown a well-ordered cone-like LDH structure. From TGA results, around $40 \%$ of mass losses were observed through the thermal decomposition along with significant impedance response in EIS analysis. In summary, this research provides an insight on the direct synthesis of cone-shaped $\mathrm{CaAl}-\mathrm{NO}_{3}-\mathrm{LDH}$ on the aluminum surface and provides a view on the structural investigation of well-ordered, cone-shaped, uniform homogeneous LDH structure. These features would support our knowledge of control environmental friendly CaAl-LDH thin film, resultant properties and possible applications.

\section{Compliance with ethical standards}

Conflict of interest The authors declare no conflict of interest.

\section{References}

1. Bi X, Zhang H, Dou L (2014) Layered double hydroxide-based nanocarriers for drug delivery. Pharmaceutics 6(2):298-332

2. Iqbal M, Fedel M (2019) Effect of synthesis conditions on the controlled growth of MgAl-LDH corrosion resistance film: structure and corrosion resistance properties. Coatings 9(1):30

3. Iqbal MA, Fedel M (2018) The effect of the surface morphologies on the corrosion resistance of in situ growth MgAl-LDH based conversion film on AA6082. Surf Coat Technol 352:166-174

4. lqbal MA, Asghar $H$, lqbal MA, Fedel M (2019) Sorption of As (V) from aqueous solution using in situ growth $\mathrm{MgAl}-\mathrm{NO}_{3}$ layered double hydroxide thin film developed on AA6082. SN Appl Sci 1(7):666

5. Zhao J, Huang Q, Liu M, Dai Y, Chen J, Huang H, Wei Y (2017) Synthesis of functionalized MgAl-layered double hydroxides via modified mussel inspired chemistry and their application in organic dye adsorption. J Colloid Interface Sci 505:168-177

6. Huang Q, Zhao J, Liu M, Chen J, Zhu X, Wu T, Wei Y (2018) Preparation of polyethylene polyamine@ tannic acid encapsulated MgAllayered double hydroxide for the efficient removal of copper (II) ions from aqueous solution. J Taiwan Inst Chem Eng 82:92-101

7. Fan G, Li F, Evans DG, Duan X (2014) Catalytic applications of layered double hydroxides: recent advances and perspectives. Chem Soc Rev 43(20):7040-7066

8. Sun X, Neuperger E, Dey SK (2015) Insights into the synthesis of layered double hydroxide (LDH) nanoparticles: part 1. Optimization and controlled synthesis of chloride-intercalated LDH. J Colloid Interface Sci 459:264-272

9. Iqbal MA, Fedel M (2019) Effect of operating parameters on the structural growth of ZnAl layered double hydroxide on AA6082 and corresponding corrosion resistance properties. J Coat Technol Res 16(5):1423-1433

10. Dutta K, Pramanik A (2013) Synthesis of a novel cone-shaped CaAllayered double hydroxide (LDH): its potential use as a reversible oil sorbent. Chem Commun 49(57):6427-6429
11. Iqbal MA, Sun $L$, LaChance AM, Ding $H$, Fedel $M$ (2019) In situ growth of a CaAl- $\mathrm{NO}_{3}{ }^{-}$-layered double hydroxide film directly on an aluminum alloy for corrosion resistance. Dalton Trans. https:// doi.org/10.1039/C9DT01773A

12. Liu Z, Ma R, Osada M, lyi N, Ebina Y, Takada K, Sasaki T (2006) Synthesis, anion exchange, and delamination of Co-Al layered double hydroxide: assembly of the exfoliated nanosheet/polyanion composite films and magneto-optical studies. J Am Chem Soc 128(14):4872-4880

13. Okamoto K, Sasaki T, Fujita T, Iyi N (2006) Preparation of highly oriented organic-LDH hybrid films by combining the decarbonation, anion-exchange, and delamination processes. J Mater Chem 16(17):1608-1616

14. Costantino U, Marmottini F, Nocchetti M, Vivani R (1998) New synthetic routes to hydrotalcite-like compounds-characterisation and properties of the obtained materials. Eur J Inorg Chem 1998(10):1439-1446

15. Hibino T, Ohya H (2009) Synthesis of crystalline layered double hydroxides: precipitation by using urea hydrolysis and subsequent hydrothermal reactions in aqueous solutions. Appl Clay Sci 45(3):123-132

16. Szabados $M$, Mészáros $R$, Erdei $S$, Kónya $Z$, Kukovecz Á, Sipos $P$, Pálinkó I (2016) Ultrasonically-enhanced mechanochemical synthesis of CaAl-layered double hydroxides intercalated by a variety of inorganic anions. Ultrason Sonochem 31:409-416

17. Rousselot $I$, Taviot-Guého $C$, Leroux $F$, Léone $P$, Palvadeau $P$, Besse JP (2002) Insights on the structural chemistry of hydrocalumite and hydrotalcite-like materials: investigation of the series $\mathrm{Ca}_{2} \mathrm{M}^{3+}(\mathrm{OH})_{6} \mathrm{Cl} \cdot 2 \mathrm{H} 2 \mathrm{O}\left(\mathrm{M}^{3+}: \mathrm{Al}^{3+}, \mathrm{Ga}^{3+}, \mathrm{Fe}^{3+}\right.$, and $\left.\mathrm{Sc}^{3+}\right)$ by X-ray powder diffraction. J Solid State Chem 167(1):137-144

18. Bontchev RP, Liu S, Krumhansl JL, Voigt J, Nenoff TM (2003) Synthesis, characterization, and ion exchange properties of hydrotalcite $\mathrm{Mg}_{6} \mathrm{Al}_{2}(\mathrm{OH}) 16(\mathrm{~A}) \times\left(\mathrm{A}^{\prime}\right)_{2-x} \cdot 4 \mathrm{H}_{2} \mathrm{O}\left(\mathrm{A}, \mathrm{A}^{\prime}=\mathrm{Cl}^{-}, \mathrm{Br}^{-}, \mathrm{I}^{-}\right.$, and $\mathrm{NO}_{3}{ }^{-}$, $2 \geq x \geq 0$ ) derivatives. Chem Mater 15(19):3669-3675

19. Constantino VR, Pinnavaia TJ (1995) Basic properties of $\mathrm{Mg}_{1-x}^{2+} \mathrm{Al}_{x}^{3+}$ layered double hydroxides intercalated by carbonate, hydroxide, chloride, and sulfate anions. Inorg Chem 34(4):883-892

20. Aisawa S et al (2002) Synthesis and thermal decomposition of MnAl layered double hydroxides. J Solid State Chem 167(1):152-159

21. Wu Q et al (2005) Delamination and restacking of a layered double hydroxide with nitrate as counter anion. J Mater Chem 15(44):4695-4700

22. Kloprogge JT, Frost RL (1999) Fourier transform infrared and Raman spectroscopic study of the local structure of $\mathrm{Mg}-, \mathrm{Ni}-$, and Co-hydrotalcites. J Solid State Chem 146:506-515

23. Ni ZM, Xia SJ, Fang CP, Wang LG, Hu J (2008) Synthesis, characterization and thermal property of $\mathrm{Cu} / \mathrm{Co} / \mathrm{Mg} / \mathrm{Al}$ hydrotalcite like compounds. Rare Metal Mater. Eng 37:634-637

24. Venugopal BR, Shivakumara C, Rajamathi M (2007) A composite of layered double hydroxides obtained through random costacking of layers from Mg-Al and Co-Al LDHs by delamination-restacking: Thermal decomposition and reconstruction behavior. Solid State Sci 9(3-4):287-294

25. Kuang Y, Zhao L, Zhang S, Zhang F, Dong M, Xu S (2010) Morphologies, preparations and applications of layered double hydroxide micro-/nanostructures. Materials 3(12):5220-5235

26. Jaiswal A et al (2015) Synthesis of novel nano-layered double hydroxide by urea hydrolysis method and their application in removal of chromium ( $\mathrm{VI}$ ) from aqueous solution: kinetic, thermodynamic and equilibrium studies. J Mol Liq 202:52-61

Publisher's Note Springer Nature remains neutral with regard to jurisdictional claims in published maps and institutional affiliations. 